\title{
Combining epidemiological and neurobiological perspectives to characterize the lifetime trajectories of ADHD
}

\author{
Philip Shaw $^{1}$ - Guilherme V. Polanczyk ${ }^{2}$
}

Published online: 21 January 2017

(C) Springer-Verlag Berlin Heidelberg 2017

Attention-deficit/hyperactivity disorder (ADHD) has been conceptualized by DSM-5 [1] as a neurodevelopmental disorder and included in the respective category grouped with autism spectrum disorder, intellectual disability, communication disorders, specific learning disorders, and motor disorders. Neurodevelopmental disorders are thought to be the result of deviations of normal brain developmental processes and are characterized by an early onset during childhood, usually accompanied by neurocognitive deficits, and a steady course over time [2].

The concept of ADHD as a neurodevelopmental disorder has emerged from a large number of studies from convergent perspectives pointing all to that direction. Recent studies published in the European Child and Adolescent Psychiatry support this notion. With regard to early risk factors and manifestations, preterm birth and low birth weight are consistent risk factors for the disorder, and even among those children born extremely preterm or with extremely low birth weight, those with minor neurodevelopmental impairments were found to be more likely to have ADHD symptoms in a dose-response relationship [3]. At 6 months of age, signs such as motor functioning and incessant crying, and at 18 months mothers' concerns such

Guilherme V. Polanczyk

gvp@usp.br

Philip Shaw

shawp@mail.nih.gov

1 Social and Behavioral Research Branch, National Human Genome Research Institute and the National Institute of Mental Health, NIH. BB37, Bldg 31, 20892 Bethesda, MD, USA

2 Department of Psychiatry, University of São Paulo Medical School, Rua Dr. Ovídio Pires de Campos 785, São Paulo 05403-010, Brazil as difficulty to handle the child were found to be associated with an increased probability of childhood ADHD [4]. With regard to continuities and discontinuities across development, hyperactivity at age 3 years was found to be a strong predictive of poor adolescent and adult outcomes, specifically for males [5]. A follow-up of a clinical sample of children with ADHD revealed that $86.5 \%$ persisted with a DSM-5 ADHD diagnosis at late adolescence [6]. In this sample, ADHD severity and family history for the disorder revealed to be important risk factors [6]. On the other hand, a follow-up of a community sample of children revealed a general decrease of ADHD symptoms with age and only about 3\% follow a course with a high level of symptoms [7]. A meta-analysis indicated that the severity of ADHD, treatment for ADHD, comorbid conduct disorder and major depressive disorder are childhood predictors for ADHD persistence into adulthood [8].

Despite the growing literature and the general consensus pointing to ADHD as a neurodevelopmental disorder, a recent finding challenged this notion. Three independent longitudinal studies following prospectively community samples from New Zealand, UK, and Brazil from childhood to early and middle adulthood consistently revealed that most cases of adult ADHD were not continuation of childhood ADHD [9-11]. Adult ADHD cases without a history of childhood ADHD were not fully explained by comorbidities, subthreshold symptoms, and information bias. Possible explanations for these findings are that subthreshold cases in childhood emerge as cases in adulthood when demands exceed capacities. Alternatively, child onset and adult onset may be distinct syndromes, meaning that ADHD is not always a neurodevelopmental disorder. How these possible explanations can be understood from a neurobiological perspective? 
If childhood- and adult-onset ADHD are distinct syndromes, then we would expect distinct etiologies and there is already some evidence of distinct genetic risk factors. Firstly, a measure of an individual's genetic risk for ADHD across the genome (the 'polygenic risk score') predicts childhood but not adult onset forms of the ADHD [9]. Secondly, the likelihood of adult-onset ADHD arising in a monozygotic twin is not increased when the co-twin has childhood-onset ADHD [10]. Such a lack of shared risk between MZ twins suggests distinct genetic contributions for adult and childhood onsets. Finally, there is growing evidence that the risk genes for the onset of ADHD are largely distinct from those determining its course, and that genetic risk factors for childhood ADHD often do not apply to the adult form $[12,13]$.

Epidemiological evidence can also inform the search for neurobiological causes. For example, while childhoodonset ADHD shows a male preponderance, adult-onset ADHD has a more equal gender balance. Such a shift points perhaps to brain regions where sexual dimorphism emerging in late adolescence could act as a risk factor for the late onset of ADHD. Additionally, while childhoodonset ADHD shows neurocognitive features repeatedly found to be associated with the disorder (such as a slightly lower IQ), the adult onset form has a more 'intact' neurocognitive profile. However, to test the hypothesis that childhood- and adult-onset ADHD have distinct neurobiology will ultimately require imaging and cognitive assessments within a prospective, population cohort study. Will we find that the adult onset of ADHD is tied to a break away from previously typical, childhood trajectories of brain structure and function?

Alternatively, it is possible that childhood- and adultonset ADHD share very similar early onset neurobiology vulnerabilities, but among those with adult-onset ADHD, 'protective' factors in childhood-such as parental support-suppress early symptom expression. This is in keeping concepts of ADHD as a multifactorial entity, in which environmental factors can counteract neurogenetic risk, keeping symptom expression below a clinical threshold. Following this model, we might predict similar anomalies of brain structure and function in adults who have ADHD, regardless of whether symptoms had a childhood or adult onset. There is one pertinent finding, stemming from a prospective study of hyperactive boys, followed clinically from childhood into their late 30s and 40s [14]. At the final assessment when the cohort had neuroimaging, $30 \%$ of the original non-ADHD children met criteria for ADHD, that is, they had adult-onset ADHD. Interestingly, brain structure among those with the adultonset ADHD lay closer to those who were never affected by ADHD than to those with childhood-onset ADHD. While this would not support a model of shared neural vulnerabilities between early and late onset ADHD, the study looked only at brain structure. Perhaps, the neural anomalies of late onset group may lie in brain function, neurochemistry or receptor profiles.

Epidemiological studies are providing strong evidence for the possibility of adult-onset ADHD. We now turn to neurobiology to determine whether adult onset represents the late expression of early onset neurogenetic risk factors or if it constitutes a novel diagnostic entity.

\section{Compliance with ethical standards}

Conflict of interest Dr. Shaw reports no conflicts of interest. Dr. Polanczyk has served as a consultant to Shire, Johnson \& Johnson, and Teva. He has served on the speakers' bureau of Shire and has developed CME material for Shire and Janssen-Cilag. He has received royalties from Editora Manole.

\section{References}

1. APA (2013) Diagnostic and statistical manual of mental disorders, 5th edn. American Psychiatric Association, Washington DC

2. Thapar A, Cooper M, Rutter M (2016) Neurodevelopmental disorders. Lancet Psychiatry. doi:10.1016/S2215-0366(16)30376-5

3. Elgen SK, Sommerfelt K, Leversen KT, Markestad T (2015) Minor neurodevelopmental impairments are associated with increased occurrence of ADHD symptoms in children born extremely preterm. Eur Child Adolesc Psychiatry 24(4):463-470

4. Lemcke S, Parner ET, Bjerrum M, Thomsen PH, Lauritsen MB (2016) Early development in children that are later diagnosed with disorders of attention and activity: a longitudinal study in the Danish National Birth Cohort. Eur Child Adolesc Psychiatry 25(10):1055-1066

5. Smith E, Meyer BJ, Koerting J, Laver-Bradbury C, Lee L, Jefferson H, Sayal K, Treglown L, Thompson M, Sonuga-Barke EJ (2016) Preschool hyperactivity specifically elevates longterm mental health risks more strongly in males than females: a prospective longitudinal study through to young adulthood. Eur Child Adolesc Psychiatry 26(1):123-136. doi:10.1007/ s00787-016-0876-8

6. van Lieshout M, Luman M, Twisk JW, van Ewijk H, Groenman AP, Thissen AJ, Faraone SV, Heslenfeld DJ, Hartman CA, Hoekstra PJ, Franke B, Buitelaar JK, Rommelse NN, Oosterlaan J (2016) A 6-year follow-up of a large European cohort of children with attention-deficit/hyperactivity disorder-combined subtype: outcomes in late adolescence and young adulthood. Eur Child Adolesc Psychiatry 25(9):1007-1017

7. Döpfner M, Hautmann C, Görtz-Dorten A, Klasen F, RavensSieberer U, BELLA Study Group (2015) Long-term course of ADHD symptoms from childhood to early adulthood in a community sample. Eur Child Adolesc Psychiatry 24(6):665-673

8. Caye A, Spadini AV, Karam RG, Grevet EH, Rovaris DL, Bau $\mathrm{CH}$, Rohde LA, Kieling C (2016) Predictors of persistence of ADHD into adulthood: a systematic review of the literature and meta-analysis. Eur Child Adolesc Psychiatry 25(11):1151-1159

9. Moffitt TE, Houts R, Asherson P, Belsky DW, Corcoran DL, Hammerle M, Harrington H, Hogan S, Meier MH, Polanczyk GV, Poulton R, Ramrakha S, Sugden K, Williams B, Rohde LA, Caspi A (2015) Is Adult ADHD a Childhood-Onset 
Neurodevelopmental Disorder? Evidence From a Four-Decade Longitudinal Cohort Study. Am J Psychiatry 172(10):967-977

10. Agnew-Blais JC, Polanczyk GV, Danese A, Wertz J, Moffitt TE, Arseneault L (2016) Evaluation of the persistence, remission, and emergence of attention-deficit/hyperactivity disorder in young adulthood. JAMA Psychiatry 73(7):713-720

11. Caye A, Rocha TB, Anselmi L, Murray J, Menezes AM, Barros FC, Gonçalves H, Wehrmeister F, Jensen CM, Steinhausen HC, Swanson JM, Kieling C, Rohde LA (2016) Attention-deficit/hyperactivity disorder trajectories from childhood to young adulthood: evidence from a birth cohort supporting a late-onset syndrome. JAMA Psychiatry 73(7):705-712
12. Pingault JB, Viding E, Galéra C, Greven CU, Zheng Y, Plomin R, Rijsdijk F (2015) Genetic and environmental influences on the developmental course of attention-deficit/hyperactivity disorder symptoms from childhood to adolescence. JAMA Psychiatry 72(7):651-658

13. Franke B, Faraone SV, Asherson P, Buitelaar J, Bau CH, RamosQuiroga JA, Mick E, Grevet EH, Johansson S, Haavik J, Lesch KP (2012) The genetics of attention deficit/hyperactivity disorder in adults, a review. Mol Psychiatry 17(10):960-987

14. Proal E, Reiss PT, Klein RG, Mannuzza S, Gotimer K, RamosOlazagasti MA, Lerch JP, He Y, Zijdenbos A, Kelly C, Milham MP (2011) Brain gray matter deficits at 33-year follow-up in adults with attention-deficit/hyperactivity disorder established in childhood. Arch Gen Psychiatry 68(11):1122-1134 